\title{
Using Screenplays to Integrate Filmwork in the ESL Classroom
}

\author{
Michael Walker \\ Asia University
}

\begin{abstract}
Although the use of film in both ESL and EFL classrooms is widespread, the screenplay on which most films are based is almost non-existent as a language learning resource. However, its structured framework provides the opportunity to teach skills-based activities that are contextually clear, particularly when accompanied by the movie. The primary challenge in adopting screenplay work into a curriculum, especially for educators not familiar with the format, is in ensuring specific language-based learning objectives are being met, whilst also encouraging creative freedom amongst the students. To that end, this paper begins with an introduction of what a screenplay is before examining how utilizing a script can transform the traditionally passive activity of watching a movie, into a series of justifiable language tasks. The familiarity with the language used from these comprehension activities then becomes the foundation for an assessable filmmaking task where students write their own screenplay and subsequently shoot it. The final part of this paper provides instructions on how to implement the movie-making segment and marking criteria for grading.
\end{abstract}

\section{Introduction}

Despite streaming platforms providing unprecedented accessibility to media content for today's language teachers, the belief that film and TV serves only as a fringe classroom activity remains prevalent in the ESL community. That this idea has gone largely unchanged since the inception of video cassettes four decades ago is contrary to a significant body of research which 
indicates film-related activities offer viable opportunities to improve language proficiency (Chao, 2013; King, 2002; Stempleski \& Arcario, 1992). The reluctance to recognise movies as genuine frameworks for learning derives from several concerns including a lack of formalised integration into curriculums (Park \& Jung, 2016); implementation issues relating to appropriate selection from the vast array of movies available and excessive preparation in creating a methodologically sound lesson plan (Stoller, 1988); and an overall lack of confidence in justifying time spent watching a movie in class. This last point is perhaps the least researched, yet most pertinent in terms of discouraging educators from showing films to their students. Afterall, no teacher wants to be labelled lazy and so watching movies has, for the most part, been relegated to a filler activity that students do before vacation or on the final day of class when all the curriculum requirements have been met (Curtis, 2003).

To address these issues, a different approach is needed, one that uses narrative media, not as a single entity to be viewed passively in one sitting, but as a series of selectively chosen clips designed to initiate student output. This, however, is not to say that the process of conventional language learning planning should be discarded; in fact, the opposite is the case. Traditional activities such as vocabulary and comprehension exercises remain an essential component of working with film and TV and forms the scaffolding Brown (2010) refers to when partnering language learning with foreign English-language films. The importance of beginning with language activities is vital, both methodologically and as a platform for bridging into the more complex series of creative tasks that will follow. The form of these tasks is naturally open to any number of choices, but for the purposes of this paper the focus will be on students writing a screenplay and turning that into a short film.

\section{Introducing the screenplay}

Perhaps surprisingly given the abundance of academic papers on utilizing film as a learning tool in the ESL classroom (Curtis 2003; Khan, 2015; King, 2002), published research into the use of screenplays as either a supplementary resource or as the basis for stand-alone activities is minimal. Subsequently, there is a reticence to using scripts in the classroom, not least of which is due to instructors being unfamiliar with the formatting. This lack of clarity naturally leads to 
difficulties translating screenplay content into workable language tasks. Therefore, a good place to begin is with an overview of what exactly a screenplay is.

\section{What is a screenplay?}

A film's screenplay is the foundational document on which every element of the movie is based. This includes not just the dialogue, but the characterisations, the choice of locations, the production design and all other aspects seen on screen. It is written in the present tense and structured in such a way that one page of script generally equates to one minute of screen time. Unlike a novel, which has the capability of communicating a character's thoughts or even a stageplay which verbalises feelings through dialogue and soliloquies, the primary focus of a screenplay is action. This means that inner thoughts and emotions need to be externalised through observable behaviour and decision-making. Dialogue should always be in service of what the characters are doing rather than as a device for exposition.

The importance of the screenplay in cinema cannot be overstated and it could be argued that the script is in fact the most vital piece of the movie-making process (Richards, 2010). If this is indeed the case, its inclusion as a language learning supplementary tool becomes increasingly justifiable for language instructors showing films in the classroom.

\section{What benefits does a screenplay offer for language learners?}

At its most basic, a script provides a written account of the dialogue found on film and could certainly be used as a 'listen and repeat' activity, not dissimilar to the conversations found in nearly all ESL textbooks (see Figure 1). However, a screenplay offers considerably more learning opportunities when approached not as a traditional listening and speaking activity, but as a foundation for creative exploration in which language acquisition is organically embedded through context.

\section{Context}

One of the major benefits of using a screenplay is that it provides students with a clear context to the learning objectives set out by their teacher. This, perhaps more than any other 
aspect, is what separates screenplay dialogue from that found in a textbook and is highlighted in the following two examples:

\section{Figure 1}

Textbook Dialogue (from Four Corners 1)

\section{Conversation Last night}

\begin{tabular}{|c|c|}
\hline Mindy & Hi, Pete. Did you see Jennifer last night? \\
\hline Pete & Yes, I did. But the day didn't go so well. \\
\hline Mindy & Really? What happened? \\
\hline Pete & $\begin{array}{l}\text { Well, I did my laundry yesterday morning, but my } \\
\text { favorite white shirt turned pink. }\end{array}$ \\
\hline Mindy & You're kidding! \\
\hline Pete & Then I got a haircut, but I really didn't like it. \\
\hline Mindy & Oh, yeah? Did you make dinner for Jennifer? \\
\hline Pete & Well, I slept for a while, so I didn't go grocery shopping \\
\hline Mindy & Oh. Did you eat anything? \\
\hline Pete & Yeah, we did. Jennifer bought a pizza for us. \\
\hline Mindy & Really? \\
\hline
\end{tabular}

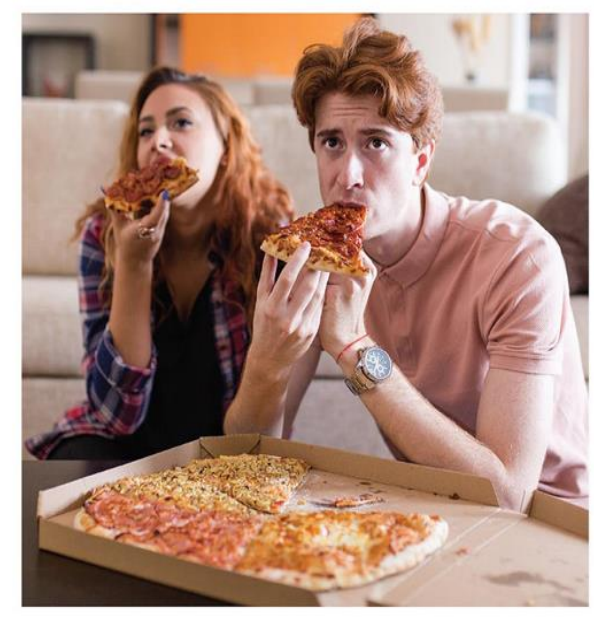

In Figure 1, we see a dialogue instantly recognizable across many language learning textbooks. It is two people talking about the previous day's events with a focus on the past tense. Whilst the conversation provides ample opportunity for students to practice the target grammar form, whether it is enabling the acquisition of practical language skills is questionable. Scepticism over the use of such activities to promote genuine language learning can be found across numerous sources including the work of Krashen. In his book, Principles and Practice in Second Language Acquisition, Krashen's central hypothesis is that language acquisition does not require an extensive use of conscious grammatical rules, nor does it require tedious drill. He elaborates further by claiming that acquisition is dependent on meaningful engagement with the target language whereby speakers are less concerned with form, and more focussed on the message they are communicating (Krashen, 1982).

If considered through this lens, it becomes clear that the conversation in Figure 1 is ineffective in terms of genuine language acquisition. This, as stated by Krashen, is due to the overriding absence of any message. The students have no idea who Mindy and Pete are, nor the 
nature of their relationship. They also do not know who Jennifer is, the subject of the conversation. Immediately this means the purpose of the dialogue is unclear. It is essentially a conversation without intent other than to practice the past tense, which, of course, holds no communicative value and stands in direct contrast to Krashen's claim that natural communication is not concerned with the way utterances are formed.

\section{Figure 2}

\section{Harry Potter Screenplay Excerpt}
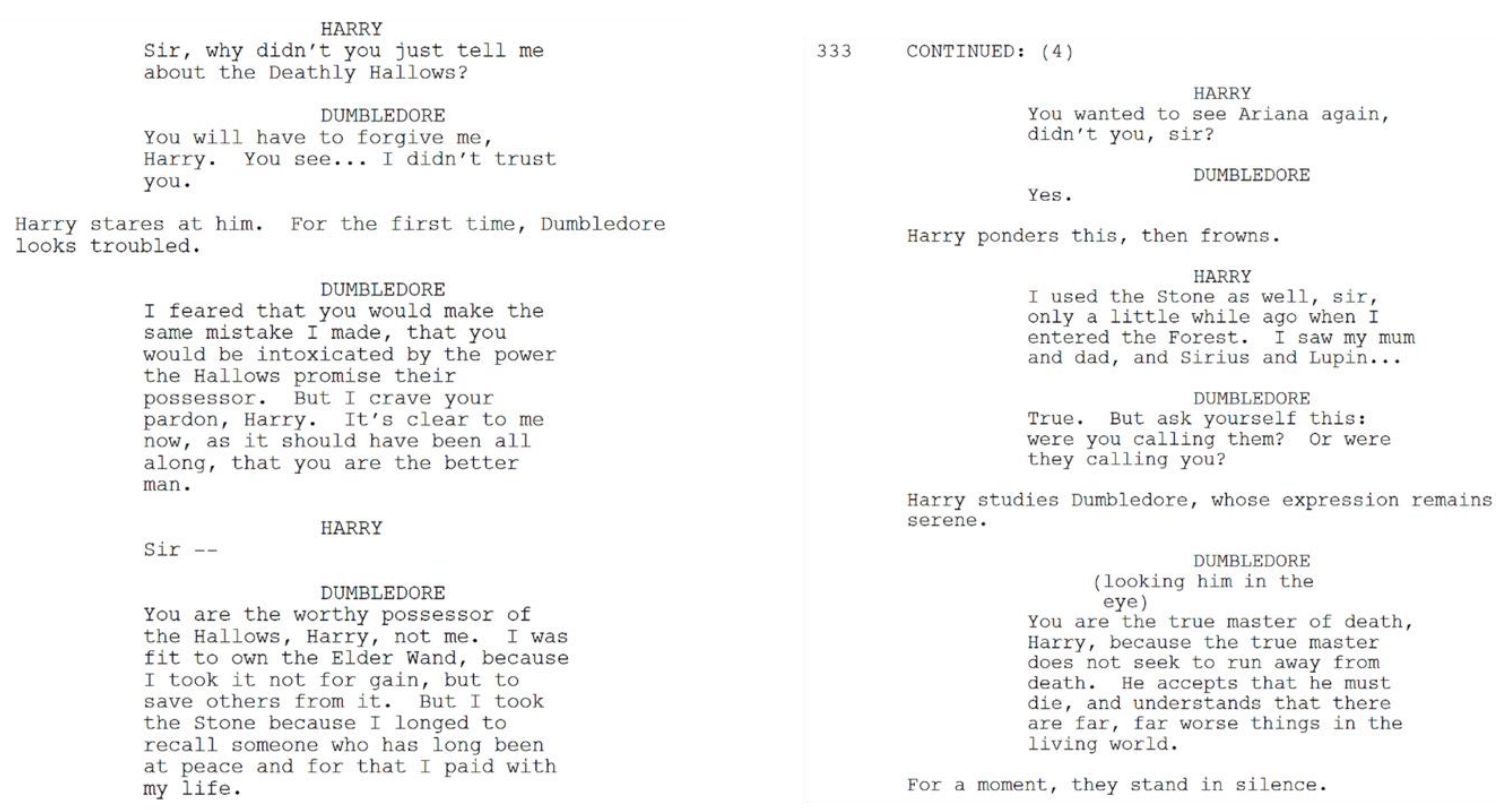

In Figure 2, this excerpt from Harry Potter's Deathly Hallows also features the use of the past tense. However, rather than a conversation with no clear speaker relationship, the dialogue between Harry and Dumbledore carries a very clear message that Harry is the rightful owner of the Deathly Hallows due to his view of death. Even without knowing the full story of Harry Potter, this short exchange is more effective in both teaching the past tense and ensuring genuine learning. This is because an artificial situation such as the one found in Figure 1 has been replaced with context-based dialogue that is recognisable from real life experience (which in the case of the Harry Potter excerpt, despite being a fantasy genre, approaches the issue of death in a very realistic way). As a result, students are motivated to engage with the learning, not only because of its recognizability but also because it has taken on a much greater level of enjoyment through the 
power of story (King, 2002). Krashen (1982) adds further support by claiming that storytelling allows the speaker to forget they are using another language and focus more fully on the message they wish to convey. In summary, the combined impact of meaningful conversation and an entertaining context leads to a far greater likelihood of genuine language acquisition.

\section{Language-related Activities}

In terms of a practical approach to language learning via screenplays, as previously discussed, the first point of engagement for students should be methodologically sound. This creates both learning objectives and alleviates concerns over the unfamiliar screenplay form that students are probably seeing for the first time.

\section{Figure 3}

Vocabulary Matching Activity

\section{VOCABULARY}

1. Dungeons \& Dragons

2. cul-de-sac -

3. Demogorgon

4. chamber

5. deep shit

6. wimp

7. bickering

8. protection spell a. to argue

b. a small room

c. a weak person

d. a type of magic

e. a role-playing board game

f. a street that goes nowhere

g. a powerful 2-headed monster

h. big trouble

In Figure 3, we have a recognisable matching activity that students almost certainly would have seen before. The language in this example is taken from the first episode of Stranger Things, a popular TV series on Netflix and one that many students may have watched. This handout would be distributed once the students had had a chance to read the script and prior to viewing the scene. The students are referencing the screenplay itself as they go through and determine the meaning of the vocabulary (see Appendix A). 
In addition, a listening activity can also be done. The teacher can play the audio of the scene and have students find any differences between what they hear and what is in the screenplay. Due to the nature of filmmaking, what was shot may differ to what was written in the script, and having students circle the differences is another language exercise that simultaneously is increasing their familiarity with the content (Appendix A).

Having read the scene, learned the new vocabulary, and completed an audio listening, a powerful bridging activity before beginning the creative component is to have students predict how the scene will look by storyboarding it.

\section{Figure 4}

Storyboard Template

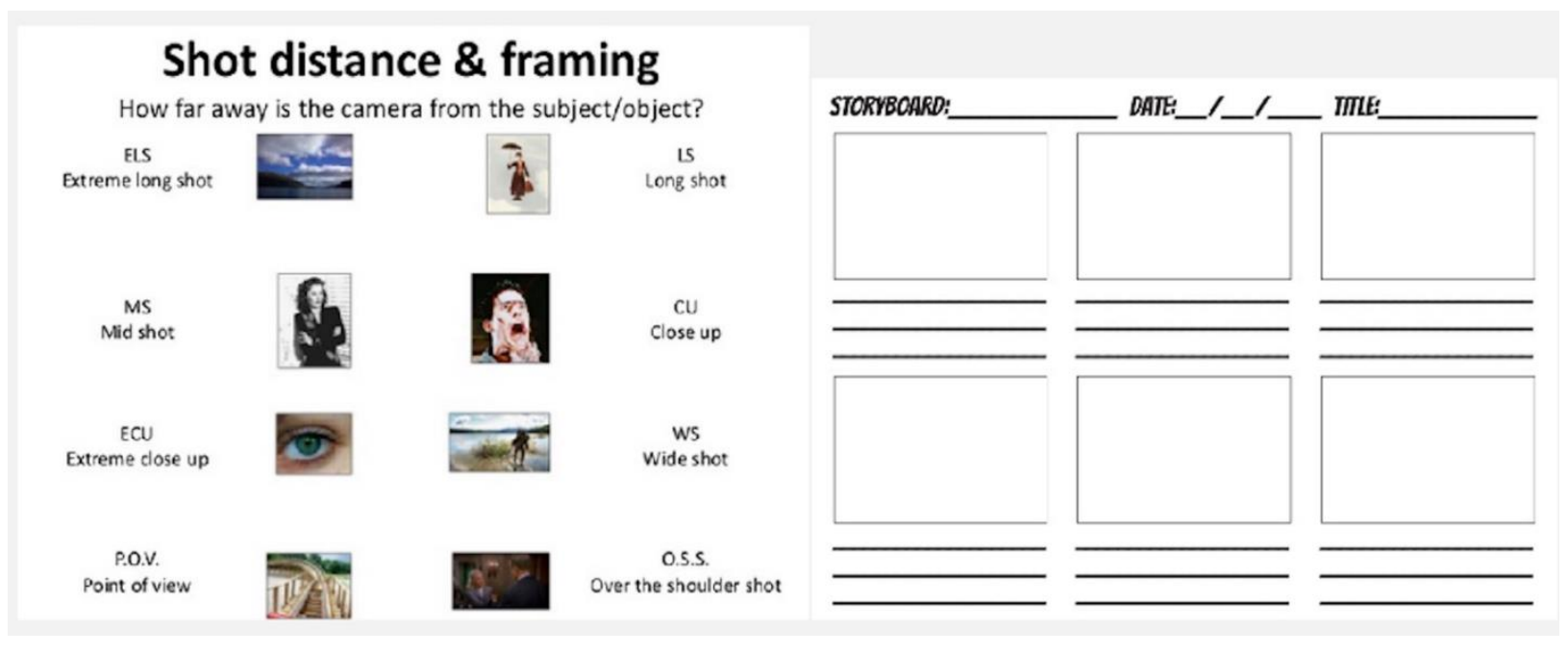

Using the handout from Figure 4 as a reference, students can be introduced to the different types of shots available for filming. Once they know the labels for each framing size, the next step is to have them guess how the scene will be directed by storyboarding it in the empty boxes (see Figure 4). This could be done either in groups or individually but is best undertaken prior to viewing the clip. As a way of guiding the students through the task, it is advisable to first give them an overview of how a scene is assembled. For example, it is common that in the beginning of a scene, the action will be viewed via a wide shot. This allows the audience to orientate themselves to the location and identify who the characters are. As the scene progresses, shots will often be edited to highlight conflict, with a mid-shot perhaps revealing body language and later a close-up 
showing the emotions on a character's face. An extreme closeup could be used at the end to emphasize the impact the scene has had. All these framing choices can serve as creative and stylistic tools the students will eventually employ in their own films.

The additional benefit of this activity is it becomes a rich source of discussion after the students have watched the scene. Comparisons between their own versions and what they saw helps them understand that film has its own visual language that extends beyond the words on the page. The process of having students imagine how the scene will play out and drawing it on the accompanying storyboard prior to viewing provides a powerful identification with the screenplay.

\section{Figure 5}

Missing Persons Activity

\section{CREATE A MISSING PERSONS POSTER}
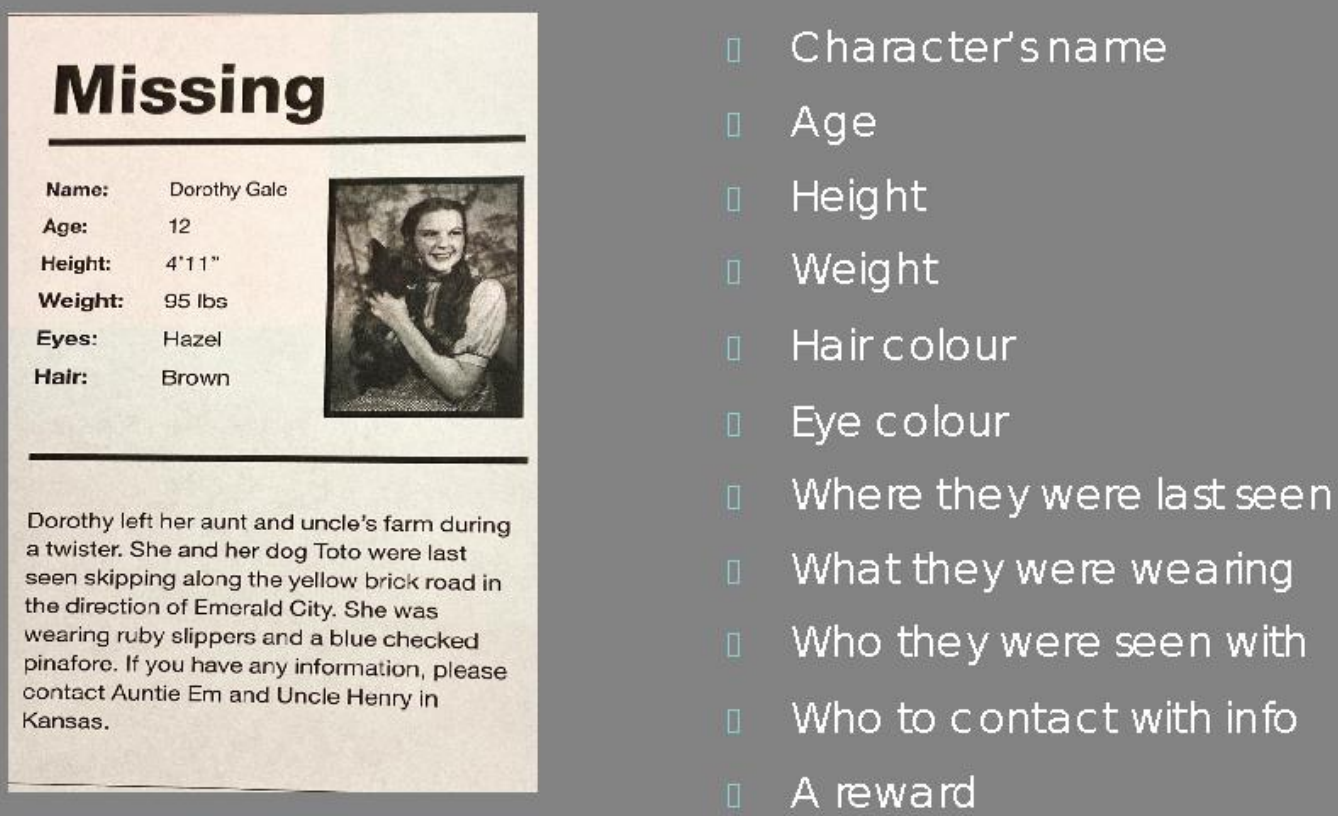

Finally, once the students have completed these activities and have watched the scene, they can be given a post-viewing exercise to further deepen their awareness of the story. The example shown in Figure 5 is effective due to the nature of its focus. The students are asked to create a missing persons poster for the main character, considering all the physical attributes and 
circumstances around their last known location. Whilst this may appear to be only suitable for genres such as crimes or mystery, hypothetical scenarios could be adapted to fit the film. For example, when Harry Potter leaves for Hogwarts, students could be asked to create a missing persons poster for him. This, like the previous work, is not only an effective way of consolidating language, but also adds another element of preparation for the screenplay the students will write themselves.

\section{Filmmaking Project}

The lead up work has ideally created a solid foundation for the main project, which is the final stage of the process. This is an important inclusion because without a creative output component, there is no way of assessing the learning that has taken place. The absence of an assessable task may subsequently reduce the incentive for course designers to integrate film work into a curriculum. We will shortly look at possible criteria that could be developed into a rubric, but for now it is important to note that when used in tandem with methodologically sound activities, a filmmaking project can be an effective and justifiable component of a language learning syllabus.

\section{Project considerations}

In considering what the project will be, time restraints need to be considered. Whilst having students make their own films is a comprehensive activity, a class schedule may not permit such a major endeavour. An abbreviated version of only writing a short script that takes up one or two lessons may be more suitable. This would still act as a valid form of assessment and could be done on an individual basis. If, however, the objective is for students to use the screenplay as a basis for a film, doing the entire project in groups is recommended. Not only does it mirror the filmmaking process, but it also allows the students to collaboratively use the language they have learned previously.

Irrespective of the final output form, one of the key steps is to provide a point of focus for the students. Without restricting the choices each group has, the task may become overwhelming 
and result in substandard story ideas. It is far better to put artificial barriers in place that will provide points of resistance for the students to navigate as they formulate their scripts.

The first, and most logical aspect to restrict is duration. In my classes, I limit the length of each film to between five and ten minutes. As one page of screenplay generally equates to a minute of screen time, this means the scripts can be no longer than ten pages.

Another thing to consider is genre. It makes sense to align the student work with the movie or TV show they have been watching. In the case of my earlier example, "Stranger Things," there is a horror component. Therefore, I tell the students this must be part of their own films, whether that be a monster character, a mystery within the story, or some other trope that matches the genre.

Depending on the vocabulary and grammar being taught, there may also be a language prerequisite. An obvious example would be incorporating a selection of the words they learned prior to watching the clip. But certainly, other syllabus-based vocabulary or grammar could be mandatory within the writing of the screenplay.

\section{Planning the story}

The first stage of any scriptwriting task is deciding on an idea. To facilitate this process, I provide the students with a work booklet that helps guide them toward the story they want to tell. They decide on the title, characters, and storyline by working through the questions in the booklet. An example of how a group completed this is provided in Appendix B.

An important point I like to make before beginning this task, however, is to clearly identify the components of a story. I structure it as a speaking activity within the groups themselves, with them generating elements essential to the story. Some of these include:

- A protagonist - the main character who wants something very specific and measurable

- An antagonist - someone or something in direct opposition to the protagonist who wants the opposite

- A beginning, a middle and an end - at the start we see the protagonist in their ordinary world, followed by an incident which has them confront a series of obstacles (the middle). The end sees the protagonist resolve the disturbance.

- Stakes - the consequences of the protagonist getting (or not getting) what they want 
- Rising action - the consequences of failure for the protagonist become more extreme

- A misbelief - the protagonist has an erroneous belief about something in their life and it is only by changing this do they become capable of achieving their objective.

By ensuring students are clear on at least some of these, their films are far more likely to be selfcontained stories rather than random skits.

\section{Script format and elements}

Once the students have a clear concept outlined, it is time to explain the script formatting and elements. Although there are free screenwriting applications that the students could use, I prefer them to write it out manually in Microsoft Word. The formatting instructions I give them are as follows:

- 12-point Courier font size

- 1.5 inch margin on the left of the page

- 1 inch margin on the right of the page

- 1 inch on the of the top and bottom of the page

- Each page should have approximately 55 lines

- The dialogue block starts 2.5 inches from the left side of the page

- Character names must have uppercase letters and be positioned starting 3.7 inches from the left side of the page

- Page numbers are positioned in the top right corner with a 0.5 inch margin from the top of the page. The first page shall not be numbered, and each number is followed by a period.

Obviously, I allow some degree of flexibility here, but it is certainly useful to provide the students with an example script they can reference in terms of both formatting and elements (see Figure 6). 


\section{Figure 6}

Screenplay Elements

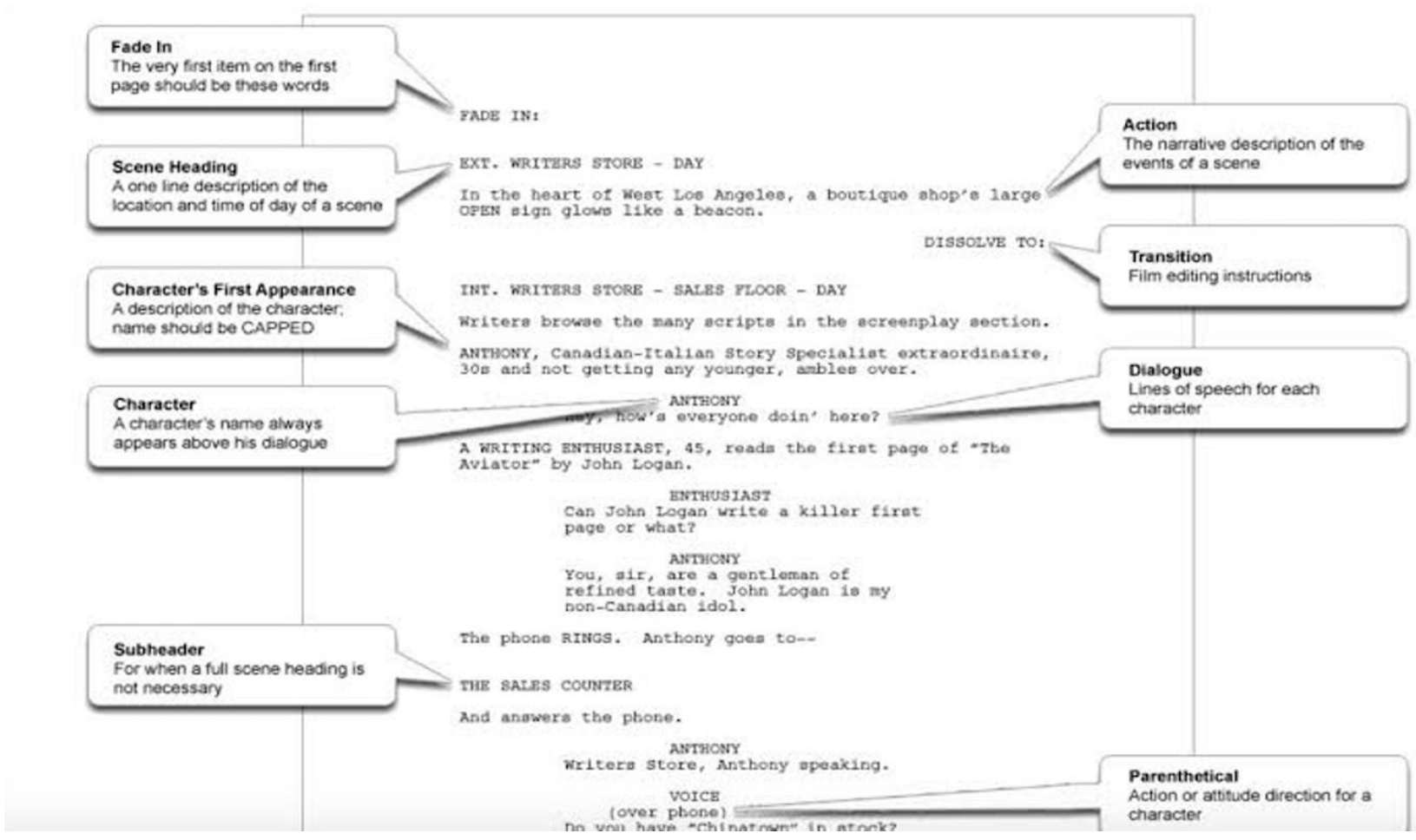

We now get to the elements, and I suggest going through this slowly as it is the first time most students will have encountered such a writing style. If we refer to Figure 6, the first element at the top of the page is labelled Fade In. This is unique only to the beginning of the script and will not be found at any other point. The next element is the Scene Heading, also known as a slugline. The slugline indicates the place and time in which a scene occurs and consists of three parts:

1. INT. stands for interior, meaning the scene is taking place inside; or EXT. which stands for exterior and means the scene is outside.

2. Next comes the actual location itself. In the case of Figure 1, we can see it's a writer's store.

3. The time. Usually, it's either DAY or NIGHT but variations such as DAWN, DUSK, and EVENING are also possible.

Following the scene heading, the next element is Action. Action segments are generally used for visual descriptions of what the characters are doing, along with other important pieces of 
information to keep the story moving forward. At the beginning of a scene, they also serve as a way of orientating the reader.

In Figure 6, after the first piece of action, there is an element titled Transition. This is essentially an edit point, and you may come across other variations such as Cut To or Fade To Black. However, these transitions have become far less common in modern screenplays and can be disregarded when teaching the form to students.

The next annotation in Figure 6 is Character's First Appearance. Although not a separate element, a standard practice when introducing a character for the first time is to capitalise his or her entire name. Usually, this is followed by a brief description of what the person looks like and any defining character traits.

After this comes Character and Dialogue. When characters are ready to speak, their names are indented and capitalised. Directly below that is dialogue, although sometimes an action or point of direction in parentheses will separate these two elements. Usually, the conversation then alternates between the respective speakers, but important action descriptions can be inserted to further elaborate on what is taking place.

Finally, if a piece of action unfolds at a specific location within the scene, a Subheader can be used. This acts as an abbreviated slugline, highlighting that whilst the action has moved to a different point, it is still part of the overall scene.

\section{Writing the script}

Once the students have been taught the formatting and elements, it is time to write the screenplay. Given their initial lack of familiarity with this type of writing, I suggest facilitating the scriptwriting process closely. Ensuring the students are using the correct formatting and elements is one area to monitor but of equal importance is providing story feedback on how to translate the ideas in their plan onto the page. This can be done by asking the students questions such as:

- What does the character want here?

- What is stopping them from going after/getting what they want?

- What action would the character take to mitigate the obstacles in their path?

- What do they want to say? 


\section{Walker: Using Screenplays to Integrate Filmwork in the ESL Classroom}

- How could they say what they want to say without stating it directly?

- What is the most efficient way to write the action using the present tense?

Although I encourage them to be linguistically accurate and offer vocabulary suggestions, my primary focus is on clarity of the story. If they write a piece of dialogue that is not grammatically correct but conveys the meaning, I often will not correct it. As previously discussed in the work of Krashen, the most important thing is the message is clear, and the last thing I want to do is remove creative ownership of the student's work in the name of lexical accuracy.

An example of the opening page of a screenplay adapted from the workbook in Appendix B, can be found in Appendix C. As you can see in the titles, their choice of wording is not perfect, but it conveyed what they wanted to say, and I was happy to leave it as the students wrote it.

\section{Production}

The groups are now ready to begin filming. This is usually done on their phones and although they are familiar with the basic workings of their cameras, I still like to spend some time explaining the more advanced features that are available for use.

On both the iPhone and high-end Androids, resolution and frame rate can be manually adjusted. For better picture quality, especially if the students are shooting in low light conditions, I suggest they use the $4 \mathrm{~K}$ resolution setting. The disadvantage of this is that files will be bigger than had they shot in HD and puts more demand on the editing device in post-production. However, good picture quality is preferable and is worth a marginally slower editing process.

The other camera setting is frame rate, with a selection of 24 frames per second (fps), 30fps or $60 \mathrm{fps}$ to choose from. The difference between the first two is that $24 \mathrm{fps}$ has a more cinematic feel, whereas 30fps looks more like television or video. The important thing is that students choose one and stay with it. For action sequences, $60 \mathrm{fps}$ is useful and captures movement with great clarity. It can be used in conjunction with the primary frame rate the students are shooting in (which is either 24fps or 30fps) as a stylistic variation. The final frame rate setting is slow motion and shoots HD at 120fps. This, when uploaded into editing software, is automatically adjusted to create a slow-motion effect. Again, this can be used with the main frame rate the film is being shot 


\section{Walker: Using Screenplays to Integrate Filmwork in the ESL Classroom}

at. The most important thing to remind students is that when choosing an effect, be it the heightened clarity of a fast frame rate or slow motion, they use it sparingly and in service of the story.

Another point to consider is that of lighting. Obviously, the students will not have the resources for complex lighting equipment, but the one thing I encourage them to employ is contrast. Rather than have light spill all over a character's face, I recommend shooting with some facial features covered in darkness. This creates a more dynamic image and creates story tension. The same principle applies to location and can be achieved by controlling where light comes from. For example, rather than using overhead fluorescent lights, the students could perhaps use light coming in from a window, a readily available lamp, or even the torch on their phone. Anything that makes the visual more interesting will help their story.

The final stage of production that students need to consider is sound quality, which can be more challenging to master than image quality. Eliminating poor audio is best achieved by recording on a separate microphone. If this is unfeasible, the audio recording on the camera can be checked after each take. Should the action or dialog not be clearly captured, another version can be recorded purely to improve sound. Usually, just this recommendation is enough to see a significant improvement in overall audio quality.

\section{Post-Production}

Once the groups have finished filming, the next stage is post-production. This includes editing, laying down a soundtrack, and exporting the finished film. In terms of the editing software students should use, I recommend iMovie and give a very short tutorial on its basic functionality. For teachers not familiar with iMovie, there are many YouTube videos on the subject you could show instead. However, should the students want to use a different program, I allow that too. At this point, I am not looking to micromanage the post-production process, but rather be available should they need me. However, in most cases, the groups are usually very autonomous throughout this stage. They have collectively invested a great deal into the creation of their stories and so are highly motivated to do the work and find solutions. The other thing I came to realise is that this generation have grown up with Instagram and Tik-Tok and many of them are very adept at 
creating video content with programs I am not familiar with. Thus, I recommend a hands-off approach, offering input only when it is requested.

In terms of exporting the finished film, MP4 format is the most suitable. Every piece of editing software will offer this video formatting option under its export tab, and the students simply need to allow time for the rendering. It is also worth mentioning that the file name should consist of the film title and any other identifying information the teacher would like, as very often students will overlook this step.

\section{Grading and final viewing}

Once the films have been exported as MP4 files, the students will upload both the movie file and the screenplay into a shared folder I have created in Google Classroom. After going through the script and movie, I will then allocate a group grade. As can be seen in in the grading criteria in Figure 7, I split the scoring into two categories: the writing of the screenplay and the making of the film. For further clarity, I subdivide these into different components including formatting, the story itself, depth of character, and use of language for writing the script, and production, postproduction, and collaboration for the filmmaking. The accompanying questions act as guidelines and can be weighted according to teacher preference. For example, in the writing section, I tend to put greater emphasis on the creative aspects of story and character rather than the technical areas of formatting and language. Likewise, I reward a highly collaborative effort even if there are technical deficiencies. 


\section{Figure 7}

Filmmaking Project Grading Criteria

\begin{tabular}{|c|c|}
\hline \multicolumn{2}{|c|}{ FILMMAKING PROJECT - GRADING CRITERIA } \\
\hline Assessment Components & Details \\
\hline SCREENPLAY - 50\% & \\
\hline Format & $\begin{array}{l}\text { - Is the script formatted correctly? } \\
\text { - Have the elements been applied accurately? }\end{array}$ \\
\hline Story & $\begin{array}{l}\text { - Is the story cohesive? } \\
\text { - Is there rising conflict in the action? } \\
\text { - Is there a clear and satisfying ending? } \\
\text { - Does the script include the pre-requisite genre } \\
\text { components? }\end{array}$ \\
\hline Characters & $\begin{array}{l}\text { - Are the goals of each character clear? } \\
\text { - Are there obstacles along the way? } \\
\text { - Does the main character undergo change by the end of } \\
\text { the story? }\end{array}$ \\
\hline Language & $\begin{array}{l}\text { - Is the dialogue engaging? } \\
\text { - Are the action elements written clearly and in the present } \\
\text { tense? } \\
\text { - Are the required language structures present? }\end{array}$ \\
\hline FILM - 50\% & \\
\hline Production & $\begin{array}{l}\text { - Does the film have dynamic camera angles and } \\
\text { - Is the sound clear? } \\
\text { - How well has the location been used (including props)? } \\
\text { - What is the quality of acting? }\end{array}$ \\
\hline Post-production & $\begin{array}{l}\text { - Is the edit smooth? } \\
\text { - Does the edit tell the story clearly? } \\
\text { - Are there any special effects? } \\
\text { - Is there a music score? } \\
\text { Is there anything particularly creative about how the film } \\
\text { has been translated from script to screen? }\end{array}$ \\
\hline Collaboration & $\begin{array}{l}\text { - Did all members of the group contribute? } \\
\text { - Were roles clearly defined? } \\
\text { - Did the group use English throughout the project? } \\
\text { - Did the group surpass expectations? }\end{array}$ \\
\hline
\end{tabular}

The final part of the project is a viewing, which I will usually stage as a film festival. If logistically possible, I have other teachers or even supervisors come in as guest judges and 
adjudicate on awards such as Best Actor and Actress, Best Screenplay and Best Film. This is always a thoroughly enjoyable experience for the students and is a good opportunity to reward individuals who have excelled throughout the project. In many cases, the students who do well are not necessarily the strongest English speakers and the chance to offer positive reinforcement to those who do not often see it in their grades is one of the truly powerful aspects of this project.

\section{Conclusion}

The process outlined in this paper is, of course, open to modification and reinvention. Whilst writing a screenplay that is subsequently made into a movie is the most comprehensive method of integrating language work and film, it is undeniably a time-consuming project that may not be suitable for all classroom environments. However, even vastly abbreviated versions of this may still carry great value for the students and will provide not only enjoyment, but also skills they can adopt into other areas. In my case, I have seen students create short, English-based videos that were then posted on their Instagram and TikTok accounts, highlighting a practical application of what they have learned in the classroom.

Another benefit has been that when we do come across a textbook conversation that is a mandatory part of the curriculum, rather than just read and repeat with no context, students are able to render appropriate meaning through discussion and in some cases, rewriting the dialogue into script format. Again, as a modified activity, these could then be rehearsed and filmed, with students adding post-production effects and uploading it as part of their classwork. The more integrated this process is into how the students approach their work, the more confident and creative they will become at adapting it. With all the technology they need readily available at their fingertips, there is no reason why script-based activities cannot make the use of film a methodologically justifiable component of any language learning environment. 


\section{References}

Brown, S. K. (2010). Popular films in the EFL classroom: Study of methodology. Procedia - Social and Behavioral Sciences, 3, 45-54. https://doi.org/10.1016/j.sbspro.2010.07.011

Chao, T.-C. (2013). A diary study of university EFL learners' intercultural learning through foreign films. Language, Culture and Curriculum, 26(3), 247-265. https://doi.org/10.1080/07908318.2013.833936

Curtis, A. (2003). Making the most of movies in the ESL classroom. From Theory to Practice: Creating Intermediate ESL Reading Materials Based on Current SLA Research and Theories, 29(3). Contact Conference Proceedings.

Khan, A. (2015). Using films in the ESL classroom to improve communication skills of non-native learners. ELT Voices, 5(4), 46-52.

King, J. (2002). Using DVD feature films in the EFL classroom. Computer Assisted Language Learning, 15(5), 509-523.

Krashen, S. D. (1982). Principles and practice in second language acquisition. Alemany Press.

Park, Y., \& Jung, E. (2016). Exploring the use of video-clips for motivation building in a secondary school EFL setting. English Language Teaching, 9(10), 81. https://doi.org/10.5539/elt.v9n10p81

Richards, B. (2010). The significance of the screenplay. Inquiries Journal, 2(2). http://www.inquiriesjournal.com/articles/172/the-significance-of-the-screenplay

Richards, J. C., \& Bohlke, D. (2012). Four corners. Student's book 1. Cambridge University Press. Stempleski, S, \& Arcario, P. (Eds.). (1992). Video in second language teaching: Using, selecting, and producing video for the classroom. Teachers of English to Speakers of Other Languages, Inc.

Tuncay, H. (2014). An integrated skills approach using feature films in EFL at tertiary level. The Turkish Online Journal of Educational Technology, 13(1), 8. 
Michael Walker has over 20 years of experience as an ESL educator in

both Australia and Japan. He has taught general English at language schools, oral communication as an ALT on the JET program, and academic skills at tertiary level. He is currently based in Tokyo and teaches academic reading and writing skills to university students. His other interests include theatre and filmmaking which he incorporates into

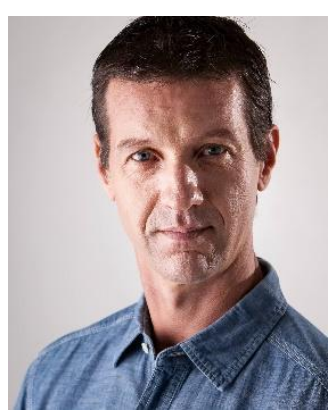
the classroom when applicable. His research areas include adopting creativity into curriculums and the impact of culture on learning attitudes.<michael@asia-u.ac.jp> 


\section{Appendix A}
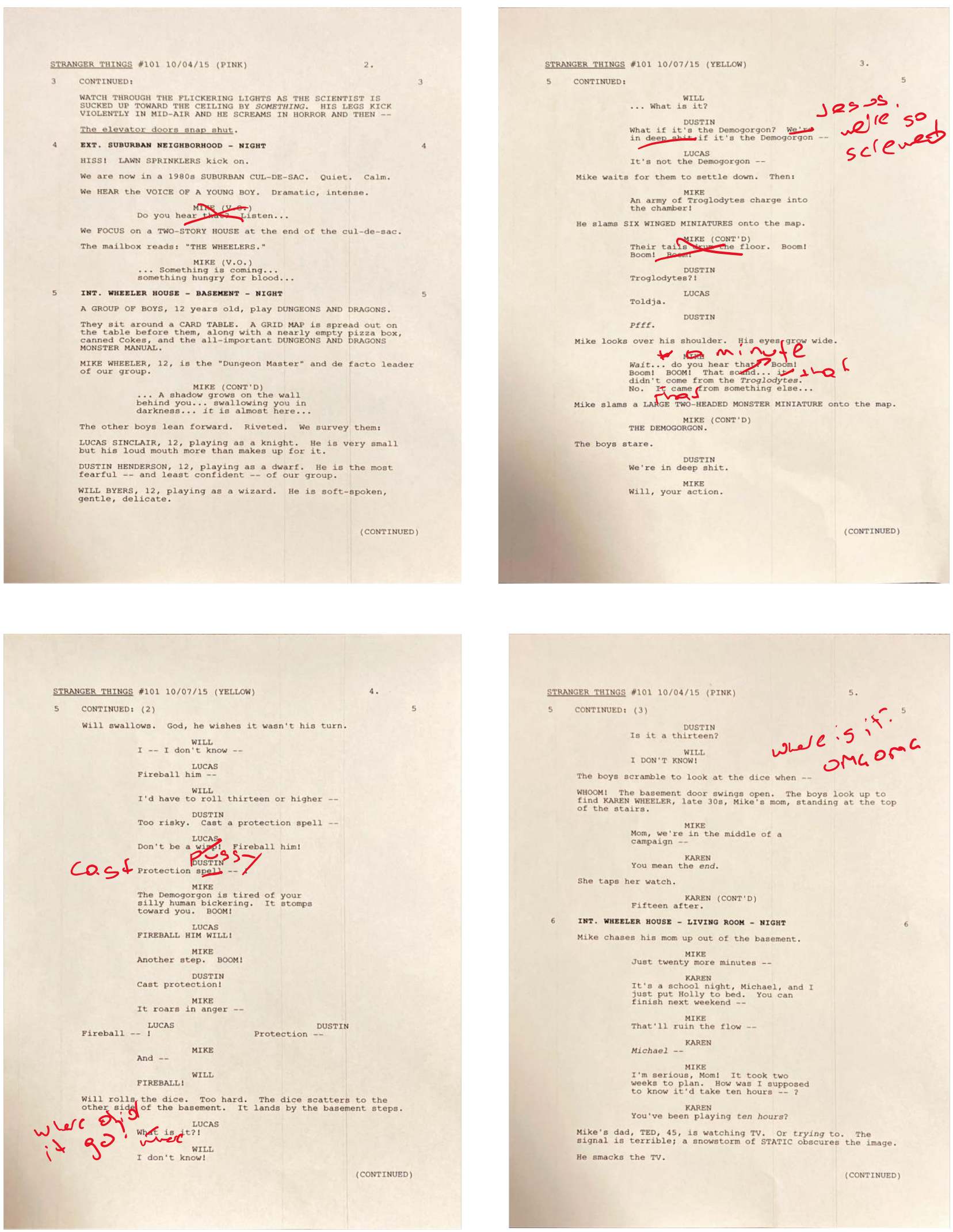


\section{Appendix B}
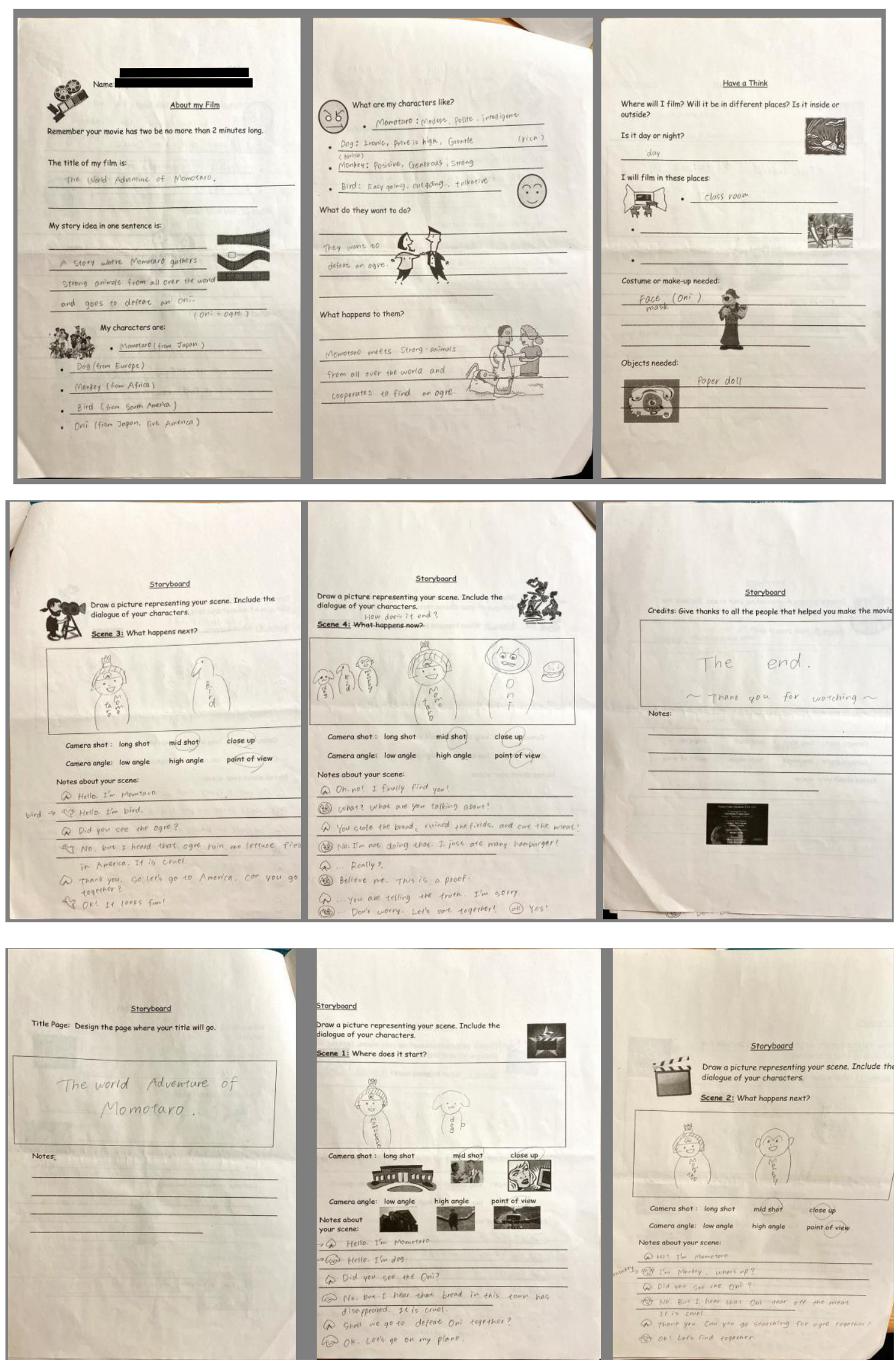


\section{Appendix C}

FADE I N:

AUAP FI LMS TI TLE

EXT. J APAN RI VER - DAY

A old lady sitting at a river.

A peach shaping object comes toward her.

She looks suprised.

ANI MATI ON FX - OLD MAP

TI TLE - In Japan, Born from peach

I NT. J APAN HOME - DAY

The old lady is with her husband. They open the peach object and see inside is baby.

They looks VERY surprised.

ANI MATI ON FX - OLD MAP

TI TLE - was gentle, polite and intelligent man. The name is Mbmot aro

See Mbmotaro become man.

ANI MATI ON FX - OLD MAP

TI TLE - He hears rumors of Oni and gather ani mals from all over the world

MONTAGE:

- EUROPE

- AFRI CA

- SOUTH AMERI CA

ANI MATI ON FX - OLD MAP

TI TLE - Now, they embark on a journey of on Oni defeat

OPENI NG CREDI T:

THE WORLD ADVENTURE OF MOMOTARO 